\title{
Simulation of autonomous mobile robot using fuzzy logic
}

\author{
Nada Badr Jarah \\ University of Basra,Collage of management and economic \\ ,Statistics department \\ 3Tnadaalgarah@yahoo.com3T
}

Recived : 22\1\2018

Available online : $20 / 2 / 2018$

DOI: $10.29304 / j q c m .2018 .10 .2 .373$

\begin{abstract}
One of the most important issues in the world of robot is the development of a smart system to improve the movement of autonomous mobile robots and non-collision within the place in which it moves, which requires machine learning and development of operational capabilities in the ability to visualize, data processing and decision-making.

The aim of this research is to simulate using the fuzzy logic in the matlab program of the robot movement to avoid the obstacle and reach the required place Beside the wall. Real world is strongly characterized by uncertainty. Fuzzy logic has proven to be a conventional tool for handling such uncertainties.
\end{abstract}

Key words : Autonomous mobile robot, Sensor, Matlab , Fuzzy Logic 
1.Introduction. Autonomous mobile robots are able to sense the environment in which they move without the need for routers and are programmed according to the nature of the work they are doing. Artificial intelligence (AI) is the most exciting field in the world of robots, where artificially supported robots collect facts and information for a situation. ['] When an autonomous mobile robot moves into a real world environment that is highly uncertain, it must be able to move between rooms in an enclosed space, Follow the walls, Avoiding obstacles, and reaching its destination ..The logic of fog is proven to be a traditional tool to address such uncertainties. It compares them with the data they store, and robots have a clear importance as a tool for mobility and operation without human in hazardous environments and difficult work such as research On mines and space, in nuclear reactors or in an environment containing toxic gases. autonomous mobile robots are capable of accomplishing tasks with higher precision than human performance, and mobility information is captured by sensors in distance measurement and analysis of the images they receive on a special computer installed inside. [2] There are several types of robots, some types of robot as application (medical, educational, space, agricultural, and to help the disabled), and the type according to the geometry (diagonal - cylindrical - spherical ) [3].

2. The aim of research. The aim is simulate the mobile robot self-movement and equipped with 5 sensors to obtain information in the movement without prior knowledge of the environment of two-dimensional and using fuzzy logic to reach the goal next to the wall while avoiding the symptoms.

Where the mobile robot determines its address towards a certain point and starts moving in a straight line towards that point. At any given moment an object or obstacle can be encountered so the mobile robot moves around the object, and correct its path, then continue to move, with repeating these actions until reaching the target point.
The software simulation was done using MATLAB because it provides an easy-to-use environment for technical computing in Graphical User Interface (GUI) building, modeling, pattern simulation, algorithmic development, and data analysis.

\section{The practical side}

3.1 Autonomous mobile robot. Robot is an automatic device capable of movement has a computer vision, which makes it autonomous in the implementation of tasks and self-movement Collecting and extracting information from the external environment using sensors and behavior according to a programmable program can be modified to change the functions of robots by writing a new program on the computer It is characterized by artificial intelligence(AI) and in the ability to distinguish patterns and identify systems, reasoning and conclusion, today's robots have become a key part of our daily lives is able to perform many tasks repeatedly and accurately without human interference . and the following operations by the mobile robot Autonomous:

1) Acquire complete knowledge of the surroundings and locations of obstacles so that they can navigate according to the sensor device data.

2) Perform a predetermined task independently without human intervention.

3) Improve the path by taking the shortest way to reach the goal while avoiding obstacles.

4) Read the sensor data continuously and correct its movement depending on the data and changes in the surrounding environment.

The autonomous mobile robot used in the simulation is equipped with four wheels to drive independently and for each two wheels on each side a separate engine to give the mobile robot the ability to move in a straight line with stability. The following are the main components of the robot used in this research:

- Computer or control system: the mastermind in the robot is the processor charged with the application of algorithms for the robot.

- Sensor system: is a tool that converts the physical effect into an electrical signal to help the robot in sensing the external influences. 
- Engine: It is the part responsible for the movement of the robot which is in the wheels

- Charging device: Batteries and a small charger to recharge the battery

3.2 Sensors. It is the basic tool of the robot to interact with the surrounding environment based on sensor readings which represent the detection and measurement of an aspect of the environment and produce an electrical signal to be processed by the robot computer to perform response functions accordingly. It simulates biological sensors such as hearing, sight and touch, which are neuro-based while robotic sensors are based electrically, robotic sensors are classified as follows: [4]

First: Sensors measuring the values that are related to the robot system such as, speed of motors, load of wheels, battery voltage.

Second: Get information about the Android environment. Such as, distance measurement, light intensity. To be interpreted by the robot.

The robot used in this research has 5 sensors for infrared (IR), each sensor is separated by $45^{\circ}$ and the five sensors are $\mathrm{F}$ for the front, $\mathrm{R}$ for right, $\mathrm{L}$ for left, CR for right sensor center and CL for left sensor center where these sensors are used for line tracking Avoid obstacles as in Figure (1), The infrared sensor is made up of an infrared source and detector. The source and detector are placed in different directions of the robot. When it is done, Face obstacle, light is reflected

Infrared off obstacle. Was detected about this thinking and then processed by the Central Processing Unit (CPU) on robot [5].

\subsection{The intelligent robot. When} designing a robot, one must determine how it behaves, where there are many robotic behaviors [6]. The robotics system is called "intelligent" If it can self-determine the choices in its decisions to simulate the solutions needed or the experience stored in the form of rules in its own knowledge base.
Autonomous mobile robot identify options in its decisions to emulate solutions or experience stored in the form of rules in its own knowledge base. an Autonomous mobile robot can be considered an intelligent system has ability to Decision-making and performing certain functions independently without human, and from intelligent robot behavior:

First: follow a predetermined path by placing a mark on the ground in form of black or white stripe affixed to the ground or field magnetic . [4] Second: Trace the walls which similar to trace lines draw on the ground. [7]

Third: Optimal path planning for the robot when moving in an unknown environment and modifying it based on actual sensor device values of the robot with the expected values. [4] Fourth: the technique of intelligent behavior Is represented of the mobile robot in the determination of the one starte point or a series of goal points, and then calculate the distance between the two points and the amount of angle determined by the robot to start moving forward and then stop at the end of the calculated distance, in addition to the use of sensors to detect any obstacle .

Fifth: Design the algorithm to avoid obstacles to enable the robot to change course due to the reaction of sensors during the movement of mobile robots.

3.4 Fuzzy logic. Is one of an artificial intelligence technique (AI) to definition of complex models with variables and simple fuzzy rules and understandable Which provides a precise mathematical method for dealing with imprecision and allows for the use of qualitative specifications.

It is a logical system based on the generalization of logic traditional bivalent. In narrow meaning, it is theories and techniques that use fuzzy sets that are sets without Conclusive boundaries.[3]

This logic represent an easy way to describe and represent human experience, and it is present practical solutions to real problems and that solutions are cost effective and reasonable. 
One of the processes on the fuzzy groups is the opposite, the merging and the intersection. [8] and the logic theory is to fill many gaps in the known classical logic, and the fuzzy set is appropriate tools to deal with uncertain and inaccurate data in intelligent decision-making systems. The contents of the collection are called members or elements. The group and its components must have two conditions, that is all elements are distinctive non-recurrent, and be clear in terms of the relationship between them.

And the fuzzy logic have many successful applications in a wide range of fields such as communications and networks [9], time series prediction [10] and the robots have also many applications in the fields of information science and control systems.

\section{Application side}

\subsection{Building a fuzzy logic system. say}

that $\mathrm{C}$ is a fuzzy set of $\mathrm{X}$ that defines the function of belonging $\mathrm{F}$ and write:

$\mathrm{FC}(\mathrm{x})$ function binds each element $\mathrm{x}$ from $\mathrm{X}$ to a value in the real field $[0,1]$. The closer the FC (x) of one is, the greater the degree of belonging of $\mathrm{X}$ to $\mathrm{C}$. It has the following logical operations: EMPTY : If $\mathrm{FC}(\mathrm{x})=0$ for all $\mathrm{x}$ values.

EQUAL: $\mathrm{C}=\mathrm{B}$ if $\mathrm{FC}(\mathrm{x})=\mathrm{FB}(\mathrm{x})$ for all $\mathrm{x}$ values.

NOT : FC $(\mathrm{x})=1-\mathrm{FC}(\mathrm{x})$

CONTAINNMENT: $\mathrm{C}$ is contained in $\mathrm{B}$ if $\mathrm{FC}$

$(\mathrm{x})<\mathrm{BC}(\mathrm{x})$ is for all $\mathrm{x}$ values.

UNION: $\mathrm{A}=\mathrm{C}$ or $\mathrm{B}$ according to rule: $\mathrm{AF}(\mathrm{x})=$ $\operatorname{Max}(\mathrm{FC}(\mathrm{x}), \mathrm{FB}(\mathrm{x}))$

INTERSECTION: $\mathrm{A}=\mathrm{C}$ and $\mathrm{B}$ according to rule: $\mathrm{AF}(\mathrm{x})=\operatorname{Min}(\mathrm{FC}(\mathrm{x}), \mathrm{FB}(\mathrm{x}))$

The Fuzzy group expresses the degree of belonging of the element to a group, and its characteristic allows it to estimate values between 0 and 1 . If $U$ is a group of objects that are generally encoded by a, a fuzzy set $\mathrm{C}$ is defined in a as a set of pairs Required [6]:

$$
\begin{gathered}
\mathrm{C}=\{(\mathrm{a}, \mu \mathrm{C}(\mathrm{a})) \mid \mathrm{a} \in \mathrm{U}\}------(1) \\
u_{C}(U) \in[0,1]
\end{gathered}
$$

Where $\mu \mathrm{C}$ (a) is called the membership function for the fuzzy set $\mathrm{C}$, When $\mathrm{U}$ is continuous, $\mathrm{C}$ is usually written as follows :

$$
C=\int_{a} u C(a) / a----(2)
$$

Where the symbol $\int$ does not indicate integration but indicates the collection of all points.

The fuzzy logic system (FLS) is created by a fuzzy sets components of four basic as shown in Figure (2) :

First : fuzzification The input variables, such as input signals, are taken from the sensor to a fuzzy amount. If it is absolutely certain that the input variable belongs to a fuzzy set, it is 1 and does not belong to 0 . [11]

Second : Fuzzy rule base Contain a set of fuzzy rules or rules in the form (if - then), the role the rule-base is not limited only to the process of storing laws, but extends to determining the availability of conditions by evaluating the first part of the laws using the process of semantics, which in turn applies logic operations from the union and intersection.[12]

Third : Fuzzy Reasoning Is the procedure in which results are obtained from the set of rules fuzzy when a particular input is achieved.

Fourth : Defuzzification It represents the gateway to exit the world of logic fuzzy by this process is converted the fuzzy linguistic values to the values non-fuzzy or numbers to make easy to computer and machines in general deal with it. 


\subsection{Mobile Robot Mathematical}

Description The mobile robot structure is shown in Figure (3)

And that his movement equation are:[13]

$\left[\begin{array}{l}\dot{x} \\ \dot{y} \\ \dot{\theta}\end{array}\right]=\left[\begin{array}{cc}\cos \theta & 0 \\ \sin \theta & 0 \\ 0 & 1\end{array}\right]\left[\begin{array}{l}v \\ \omega\end{array}\right]$

The movement of the robot is controlled by linear velocity $(v)$ and angular velocity $(\omega)$, which are described as follows:

$$
\left[\begin{array}{c}
v \\
\omega
\end{array}\right]=\left[\begin{array}{cc}
1 / 2 & 1 / 2 \\
-1 / 2 k & 1 / 2 k
\end{array}\right]\left[\begin{array}{l}
v_{f} \\
v_{k}
\end{array}\right]
$$

The equations above are used to construct a model for an autonomous mobile robot where simulations are performed using Simulink toolbox blocks in MATLAB.

\subsection{Simulation of autonomous mobile} robot in the MATLAB The application of this system is practically done by computer after the determination of the totals and the development of the laws. The autonomous mobile robot model was built using the equations above (3 \& 4) and simulink simulation in Matlab is particularly useful for generating approximate solutions of mathematical models that may be It is potentially difficult to solve "by hand" as well as mathematical equations that describe kinematics of the mobile robot [14]. The flowchart (1) presents the autonomous mobile robot simulation algorithm:

Especially blocks are created by write the simulation $\mathrm{S}$-function the where providing a powerful mechanism to expand the capabilities of the Simulink environment, and the description of the computer language of the Simulink block written in Matlab. S- is compiled as files using the mex utility, In which the $\mathrm{S}$ functions are dynamically routine linked, which Can the execute engine Matlab and executed automatically.
Uses S-function a special structure called API S-function Which enables you to interact with the engine Simulink. This interaction is very similar to the interaction between the engine and the built in Simulink blocks. And the write of Sfunction block is a complete construction of the mobile robot (Android platform, Android sensors, environment) for direct simulation.

S-function follows a general model and can accommodate continuous, discrete and hybrid systems. By following a set of simple rules, you can implement an algorithm and use the Sfunction block to add it to the Simulink model. You can also customize the user interface, and the code to generated S-function code by writing a Target Language Compiler (TLC) file.

The inputs for the robot movement to the goal are as follows:

$\theta$ : it represents the heading angle of the autonomous mobile robot. It is measured in radians.

$\boldsymbol{X}_{\boldsymbol{n}} \& \boldsymbol{Y}_{\boldsymbol{n}}$ : represent coordinates of the current position of the autonomous mobile robot center are measured in meters.

$\boldsymbol{X}_{\boldsymbol{m}} \& \boldsymbol{Y}_{\boldsymbol{m}}$ : represent coordinates of the current position of the goal point position are measured in meters.

$\mathbf{t}$ : Represents the current simulation time and is measured in seconds.

by Using sensors for Front, Right, Left, Right Center and Left Center respectively Is measured The distance between the mobile robot and the obstacle is as it exists. and Generally, the collision or reaching the target is in value 1 where the result is stop and non-collision or failure to reach the target the value 0 .

When sensing the presence of an obstacle by the sensors F, R, L The control of obstacle avoidance (OAFC) is activated, either when sensing the CR sensor near the right wall, the right-wall avoidance control (RWFC) is activated then when sensing the CL near the left wall, Left-wall avoidance control (LWFC) is activated. 
create Obstacle Avoidance Fuzzy Controller (OAFC). When reporting an obstacle detector, the autonomous mobile robot changes its orientation to follow another path without collision. This uses three inputs for the front, right and left distances determined by sensors F, $\mathrm{R}$ And $\mathrm{L}$ respectively are either ( near or far).

The outputs are the angular velocity of the right wheels $\mathrm{W}_{\mathrm{R}}$ and the left $\mathrm{W} \mathrm{t}$ and have four functions which represent Fast to the Back (BF), and Slow to the Back (BS), Fast Forward (FF), and Slow Forward (FS), as in Table (1).

And the figure (4) illustrates the autonomous mobile robot path and avoids the obstacle using OAFC.

The fuzzy control techniques are applied to maintain the robot movement of wall side Left LWFC or Right RWFC and it is also obstacle It depends on the goal point (xm, ym) in determining proximity and distance from the wall. And the continued mobility of the autonomous robot alongside the wall. Input units are in the Right Wall-Fuzzy Controller (RWFC) are the distance to the right wall and are determined by the sensor reading $(\mathrm{CR})$ of the autonomous mobile robot and $\theta_{\text {diff }}$ which represents the difference between the Azimuth (the mobile robot heading angle), and the goal angle $\left(\theta_{\mathrm{g}}\right)$. it is measured in degrees. It has 5 fuzzy groups: zero $(\mathrm{Z})$ ، Small Negative (SN) ، Small Positive (SP), Big Positive (BP) ، Big Negative (BN) .

The outputs are the angular velocity of the right wheels $\mathrm{W}_{\mathrm{R}}$ and the left $\mathrm{W} \mathrm{l}$, as in Table (2)

The Fuzzy Controller system Left Wallfollowing Fuzzy controller (LWFC) which is used to propel the autonomous mobile robot in a parallel path to the left wall, has two inputs, namely the distance to the left wall, and is determined by the sensors reading LR of the autonomous mobile robot and $\theta_{\text {diff }}$, which represents the difference between the Azimuth ( mobile robot heading angle), and the goal angle $\left(\theta_{\mathrm{g}}\right)$. it is measured in degrees. The outputs are $\left(\mathrm{W}_{\mathrm{R}}\right.$ and $\left.\mathrm{W}_{\mathrm{l}}\right)$ as in Table (3)

The controllers will be integrated RWFC \& LWFC in operation with the OAFC controller that was built.
The simulation results for the proposed approach are shown in Figure (5) and the coordinates of the goal point are $(15,16)$.

5. Conclusions. The search for the best path that the robot can take to reach its goal is still obsessed with researchers and the most growing research.

Has been applied modern control techniques such as autonomous mobile robot control systems in unknown environments. The nonlinear model of the mobile robot was used mathematically, and in practice the simulation was done using the simulink tools available in the Matlab program.

Fuzzy logic has been used in the design of the console to avoid collisions with obstacles (OAFC) The next fuzzy control unit is able to align the mobile robot along any wall، both on the right side (RWFC) Or left side(LWFC) Of the robot, which may stand between the robot and the target point. Finally, all of the above mentioned are combined and be controlled together, using a specially designed block called a supervisor switch block, and applied to the mobile robot. The latter was able to perform a collision-free path up to a certain target.

6. Recommendations. In light of the results of the research, the following recommendations can be formulated:

1) The robot can imagine what the next procedure should be and then act Based on the best results And depending on a knowledge base as an important part of expert systems

2) Implementation of the proposed console in practice using the mobile robot system in real world environments

3) Investigate increasing the type and number of sensors and / or location on the robot to determine the appropriate number of them according to the detection format, the number of obstacles, the optimal path ... etc. 
4) Additional components can be added to robot making their work more complex and can lead to more complex behavior, such as adding a camera unit to robot. Add camera needs image processing capabilities that can give robot the ability to recognize patterns, face recognition, ... etc

5) Investigate the use of various localization devices and algorithms such as the Global Positioning System (GPS) to improve the localization of the mobile robot.

6) Study the movement of dynamic obstacles in the unknown environment.

\section{References}

[1] Gerlind Wisskirchen ,Blandine Thibault Biacabe,Ulrich Bormann , Annemarie Muntz,Gunda Niehaus,Guillermo Jiménez Soler,Beatrice von Brauchitsch, "Artificial Intelligence and Robotics and Their Impact on the Workplace" ,April (2017).

[2] Gyula Mester," Intelligent Mobile Robot Motion Control in Unstructured Environments", Department of Informatics, Robotics Laboratory, University of Szeged, Acta Polytechnica Hungarica, Vol. 7, No. 4, (2010)

[3] Roland Siegwart and Illah R. Nourbakhsh, "Introduction to Autonomous Mobile Robots", Massachusetts Institute of Technology, A Bradford Book, The MIT Press, Cambridge, Massachusetts, London, England, (2004).

[4] Deepak Punetha, Indian Institute of Technology Patna and, Neeraj Kumar, Chitkara University, and Vartika Mehta , Seemant Institute of Technology, Pithoragar ,"Development and Applications of Line Following Robot Based Health Care Management System", August (2013)

[5] Gordon McComb, and Myke Predko, "Robot Builder's Bonanza", third edition, The McGrawHill Companies, Inc., 1987, 2001,( 2006).

[6] Castillo, Oscar, Melin, Patricia , "ype-2 Fuzzy Logic: Theory and Applications", (2008).

[7] Mehmet Ergezer, Multivariable," Control Methods for Wall Tracking Robot", Cleveland State University, Department of Electrical and Computer Engineering, Project Paper, (2006).

[8] Marcel Dekker, Editors: A. Kent, J. G. Williams, "Fuzzy Logic in Artificial
Intelligence", In book: Encyclopedia of Computer Science and Technology", Chapter: Vol. 34, Suppl. 19, Publisher:, pp.179-190, July (1997)

[9] Amrita Sarkar $_{1} \quad$ G.Sahoo 2 and $\mathrm{U} . C . S a h o o_{3}$,"APPLICATION OF FUZZY LOGIC IN TRANSPORT PLANNING"1 Research Scholar, Department of Information Technology, B.I.T Mesra, Ranchi, amrita.manna@gmail.com , 2 Professor and Head,Department of Information Technology, B.I.T, Mesra, Ranchi , gsahoo@bitmesra.ac.in ,3Assistant Professor, Department of Civil Engineerng, I.I.T, Bhabaneswar , ucsahoo@iitbbs.ac.in , International Journal on Soft Computing (IJSC) Vol.3, No.2, May (2012).

[10] Martin ·Stepnicka, Viktor Pavliska, Vilem Novak, Irina Perfilieva, Lenka Vavrickova, Iva Tomanova,"Time Series Analysis and Prediction Based on Fuzzy Rules and the Fuzzy Transform", University of Ostrava , Institute for Research and Applications of Fuzzy Modeling, 2009.

[11] V. M. Peri, "Fuzzy Logic Control for an Autonomous Robot", M.Sc. thesis, Cleveland State University Cleveland ,Ohio ,USA, May,( 2005).

[12] Edward Tunstel, Tanya Lippincott and Mo Jamshidi ,"Introduction to Fuzzy Logic Control With Application to Mobile Robotics", NASA Center for Autonomous Control Engineering , Department of Electrical and Computer Engineering, University of New Mexico (2012). [13] Ching-Chang Wong, Hoi-Yi Wang, ShihAn Li, and Chi-Tai Cheng " Fuzzy Controller Designed by GA for Two-wheeled Mobile Robots" 'International Journal of Fuzzy Systems, Vol. 9, No. 1, March (2007) @ 2007 TFSA.

[14] Mariusz Giergiel ,Tomasz Buratowski , Piotr Ma lka , AGH University of Science and Technology , Department of Robotics and Mechatronics, giergiel@agh.edu.pl , tburatow@agh.edu.pl, piotr.malka@gmail.com , Krzysztof Kurc , Rzeszow University of Technology , Department of Robotics and Mechatronics , kkurc@prz.edu.pl "The Mathematical Description of the Robot for the Tank Inspection" , Mechanics and Mechanical Engineering , Vol. 15, No. 4 (2011) 5360 ,Technical University of Lodz. 


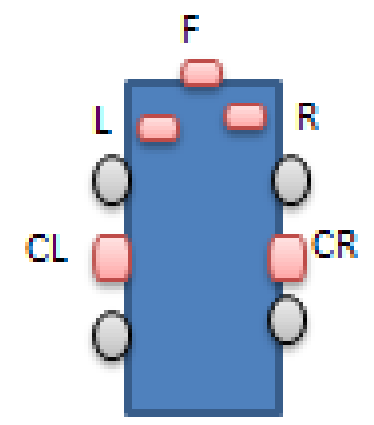

Figure (1) Location sensors

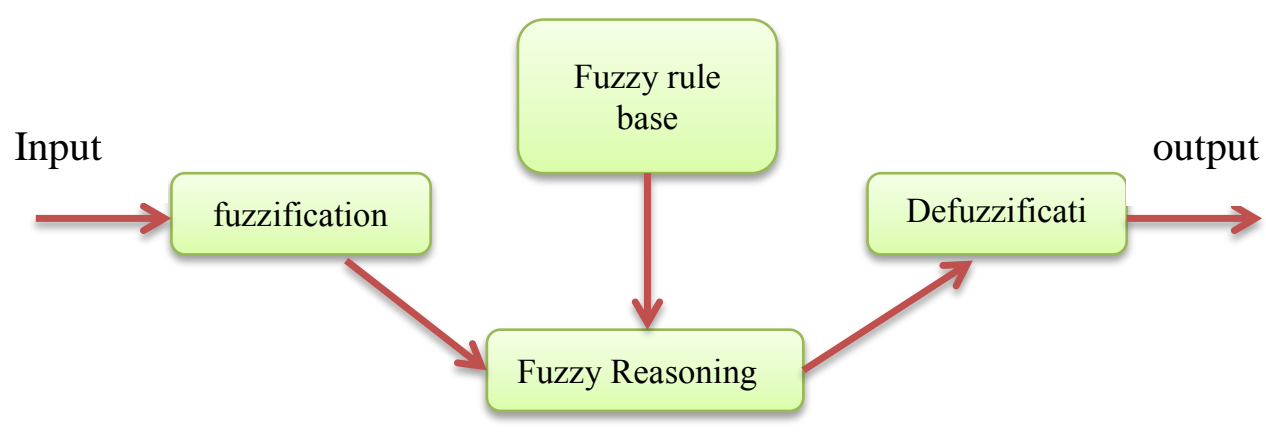

Figure (2) Fuzzy logical system

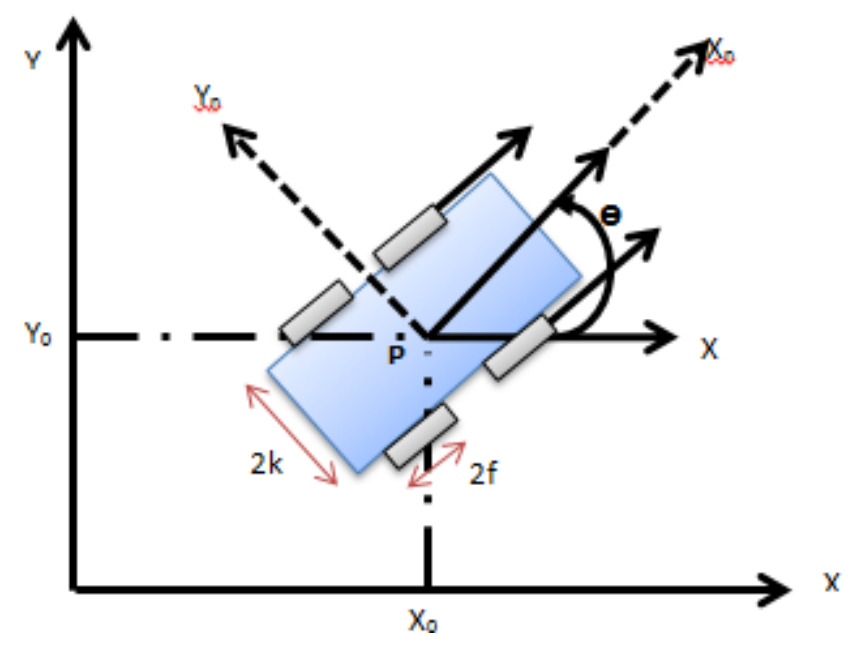

Figure (3) : mobile robot structure 


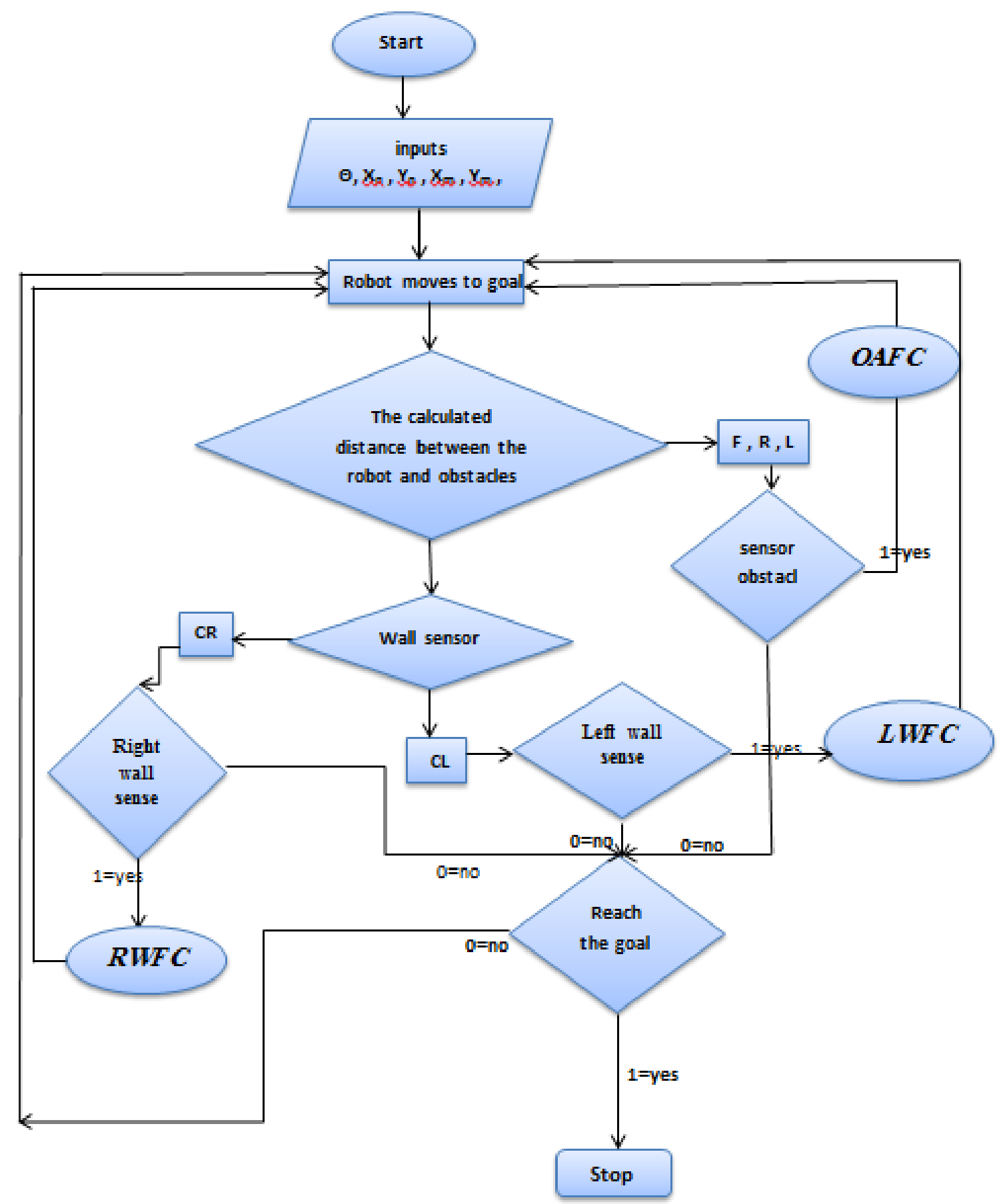

Chart (1) Flowchart for the autonomous mobile robot algorithm 
Table (1) : OAFC

\begin{tabular}{|c|c|c|c|c|}
\hline \multicolumn{3}{|c|}{ Inputs } & \multicolumn{2}{c|}{ Outputs } \\
\hline $\boldsymbol{F}$ & $R$ & $L$ & $W_{R}$ & W \\
\hline near & near & Near & BF & BF \\
\hline near & near & Far & FS & BS \\
\hline near & far & Near & BF & FS \\
\hline near & far & Far & BS & FF \\
\hline far & near & Near & FS & FS \\
\hline far & near & Far & FS & BS \\
\hline far & far & Near & BS & FS \\
\hline far & far & Far & FF & FF \\
\hline
\end{tabular}

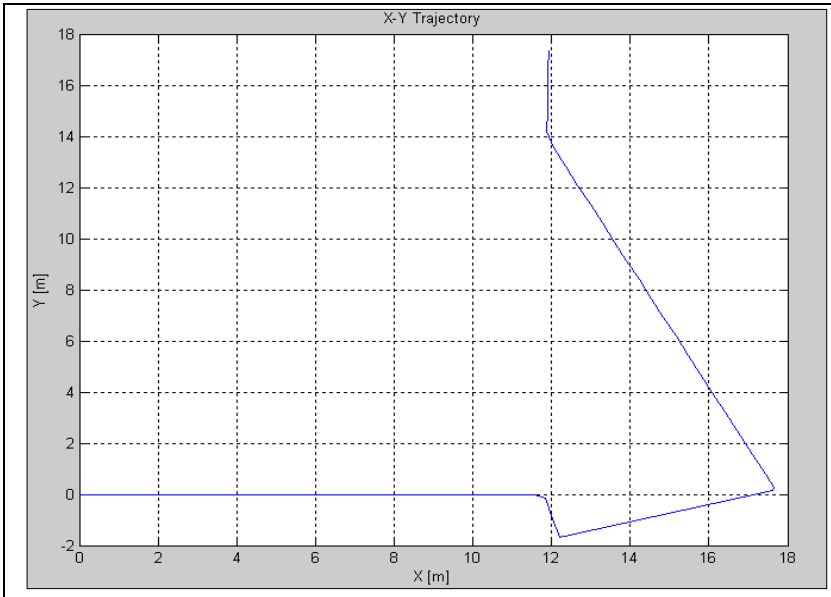

(a)

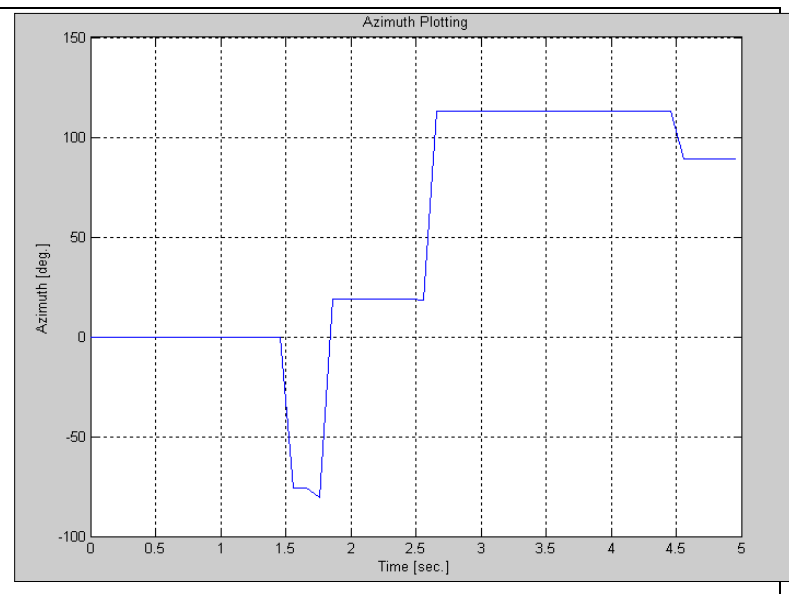

(b)

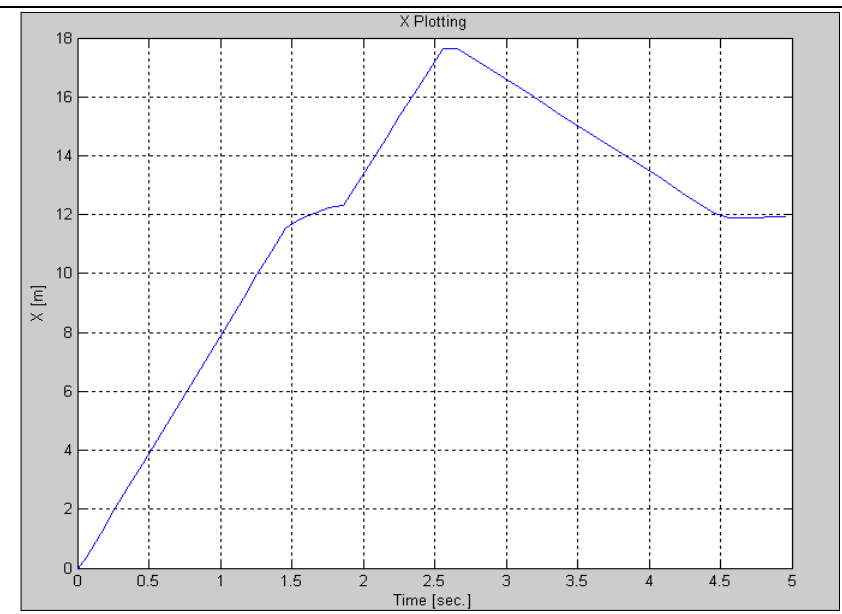

(c)

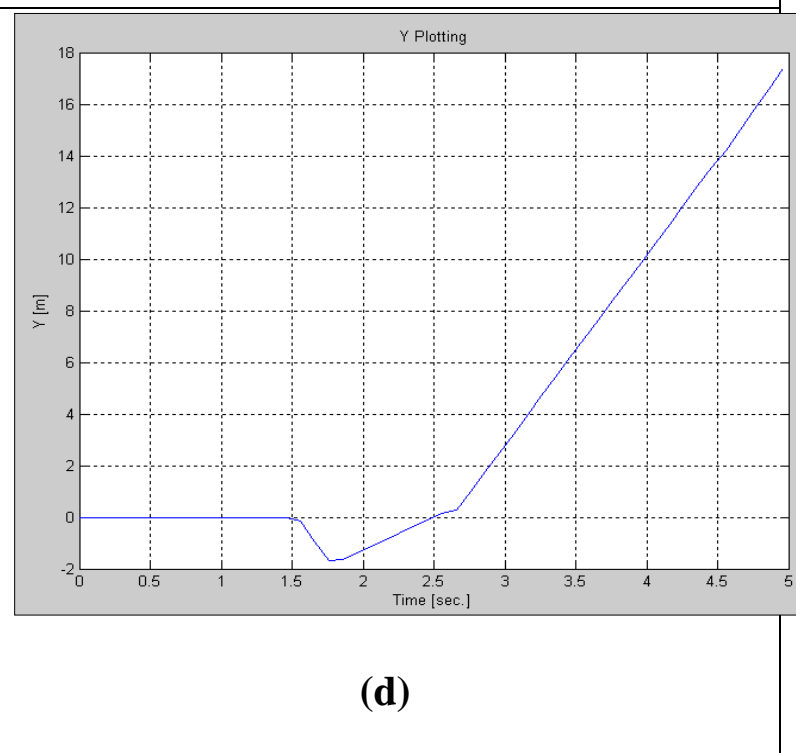

(d)

Figure(4) Plottings of (a)X-Y trajectory,(b)Azimuth, (c)X, and (d)Y with OAFC 
Table (2) RWFC

\begin{tabular}{|c|c|c|c|}
\hline \multicolumn{2}{|l|}{ Inputs } & \multicolumn{2}{l|}{ Outputs } \\
\hline $\begin{array}{c}\text { distance to } \\
\text { right wall }\end{array}$ & $\theta_{\text {diff }}$ & $\mathrm{W}_{\mathrm{R}}$ & $\mathrm{W}$ \\
\hline close & $\mathrm{Z}$ & $\mathrm{FF}$ & $\mathrm{FF}$ \\
\hline close & SN & FS & BS \\
\hline close & BN & FF & BF \\
\hline close & SP & FS & FS \\
\hline close & BP & FF & FF \\
\hline
\end{tabular}

Table (3) LWFC

\begin{tabular}{|c|c|c|c|}
\hline \multicolumn{2}{|c|}{ Input } & \multicolumn{2}{c|}{ Outputs } \\
\hline $\begin{array}{c}\text { distance to } \\
\text { left wall }\end{array}$ & $\boldsymbol{\theta}_{\text {diff }}$ & $\mathrm{W}_{\mathrm{R}}$ & $\mathrm{Wl}$ \\
\hline close & Z & FF & FF \\
\hline close & SN & FS & FS \\
\hline close & BN & FF & FF \\
\hline close & SP & BS & FS \\
\hline close & BP & BF & FF \\
\hline
\end{tabular}

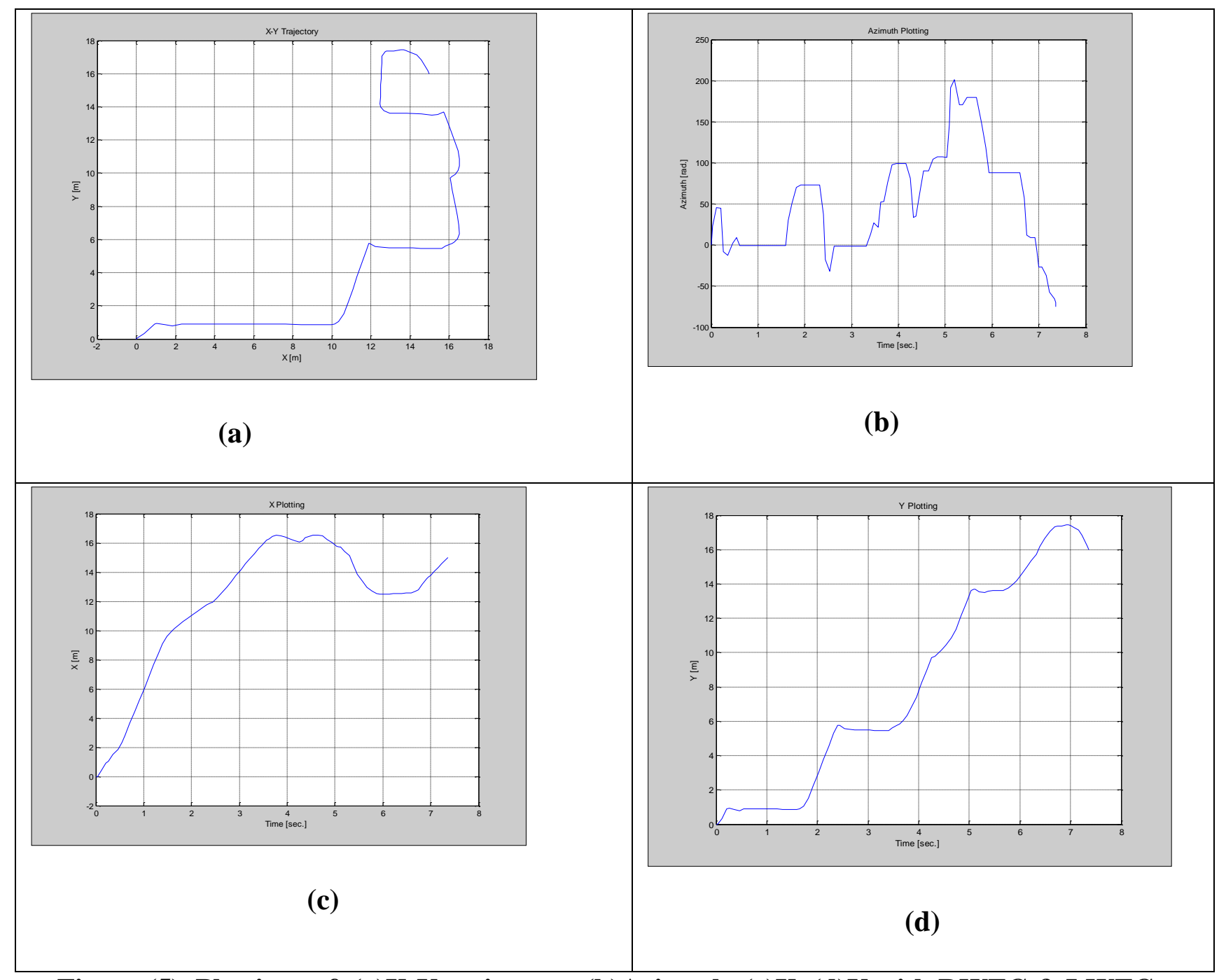

Figure (5) Plottings of (a)X-Y trajectory,(b)Azimuth, (c)X, (d)Y with RWFC \& LWFC 
محاكاة الروبوت المتنقل المستقل باستخدام المنطق المضبب

\author{
ندى بلدر جراح
}

جامعة البصرة / كلية الادارة والاقتصاد/ قسم الاحصاء

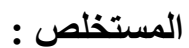

ان من اهم القضايا في عالم الروبوت هي تطوير نظام ذكي لتحسين حركة الروبوت المتنقل المستقل وعدم الاصطدام ضمن المكان

الذي يتحرك فيه ، وهذا ما يتطلب تعلم الالة وتطوير قدر اتها التشغيلية في التمكن من التصور ومعالجة البيانات واتخاذ القرار .

والهذف من هذا البحث هو المحاكاة باستخدام المنطق المضبب في برنامج ماتلاب لحركة الروبوت في تجنب العوارض

و الوصول الى المكان المطلوب بجانب الجدار. إن العالم الحقيقي يتميز بشدة بعدم اليقين. وقد أثبت المنطق الضبابي أنه أداة تقليدية لمعالجة

مثل هذه الشكوك.

الكلمات المفتاحية : الروبوت المتنقل المستقل، الاستشعار، ماتلاب، المنطق المضبب 